\title{
A Study on P16 Expression in Surface Epithelial Tumours of Ovary
}

\author{
Kalyani Prem ${ }^{1}$, Roshny Jacob² \\ ${ }^{1}$ Department of Pathology, Government Medical College, Thiruvananthapuram, Kerala, India. \\ ${ }^{2}$ Department of Pathology, Government TD Medical College, Alappuzha, Kerala, India.
}

\section{ABSTRACT}

\section{BACKGROUND}

Ovarian cancer is the $6^{\text {th }}$ most common cancer in women worldwide. ${ }^{1}$ According to Indian Cancer registries, ovaries are the third leading sites of cancer among women. ${ }^{2} 2 / 3^{\text {rd }}$ of all ovarian neoplasms are surface epithelial tumours and the majority of endometrioid and clear cell carcinomas and some serous tumours show a poor prognosis. p16, a protein encoded by the gene, CDKN2A, located in chromosome 9p21.3, plays a major role in cell cycle regulation by hindering its progression through phase G1 to S. Many studies have found a significant prognostic implication of p16 on surface epithelial tumours and thereby identify such tumours and initiate early therapy. Our study was conducted to find out any significant association of $\mathrm{p} 16$ expression in ovarian surface epithelial tumours.

\section{METHODS}

This was a cross-sectional study, done in the Department of Pathology, Government Medical College, Thiruvananthapuram from March 2018 to March 2019. 118 cases were selected, IHC analysis was done and the data were analysed using statistical software SPSS version 20.0.

\section{RESULTS}

118 cases of ovarian surface epithelial tumours were chosen for the study of which 60 cases were benign, 28 were malignant and 20 were borderline tumours. Strong p16 expression was found in $50 \%$ of malignant tumours and $81.6 \%$ of benign tumours had weak expression. This was found to be statistically significant $(\mathrm{P}=0.000)$. Also, a comparison of $\mathrm{p} 16$ expression among the various subtypes of surface epithelial tumours was found to be statistically significant $(\mathrm{P}<0.01)$.

\section{CONCLUSIONS}

The present study found a positive correlation between p16 expression in tumour cells and histopathological grades of surface epithelial ovarian tumours, with the highest expression noted in malignant tumours. A significant relation was observed between p16 expression and the subtypes of surface epithelial tumours with endometrioid and clear cell carcinomas showing the highest expression.

\section{KEY WORDS}

Surface Epithelial Tumours, Immunohistochemistry, p16 Expression
Corresponding Author: Dr. Roshny Jacob, Associate Professor, Government TD Medical College, Alappuzha, Kerala, India. E-mail: roshnyjacob@yahoo.com

DOI: $10.14260 /$ jemds/2022/28

How to Cite This Article:

Prem K, Jacob R. A study on P16 expression in surface epithelial tumours of ovary. J Evolution Med Dent Sci 2022;11(01):147150, DOI: $10.14260 /$ jemds $/ 2022 / 28$

Submission 28-09-2021,

Peer Review 18-01-2022,

Acceptance 24-01-2022,

Published 29-01-2022.

Copyright (C) 2022 Kalyani Prem et al. This is an open access article distributed under Creative Commons Attribution License [Attribution 4.0 International (CC BY 4.0)] 


\section{BACKGROUND}

Ovarian cancer is the $6^{\text {th }}$ most common cancer in women worldwide and the $7^{\text {th }}$ most common cause of cancer-related deaths. ${ }^{1,2,3}$ According to Indian Cancer registries, ovaries are the third leading sites of cancer among women, after cervix and breast. ${ }^{2} 90 \%$ of all the ovarian cancers and $2 / 3^{\text {rd }}$ of all ovarian neoplasms are surface epithelial tumours with serous tumours at the top of the list, closely followed by mucinous and endometrioid tumours. 4,5,6 Among ovarian neoplasms, 80 $\%$ are benign and are frequently seen in the age group of 2045 years whereas borderline tumours are seen at an older age. ${ }^{7,8,9}$ Premenopausal and perimenopausal females form the predominant ones to develop malignant epithelial tumours. ${ }^{10,11}$

Across the globe many mutational studies on surface epithelial ovarian tumours are now going on, to establish a proper genetic classification for determining adequate treatment protocols and proper prognostic assessment. The major ones being studied are p53, KRAS, ERBB2, BRAF \& PTEN. ${ }^{12,13}$ p16 is yet another protein studied in this context. p16, also known as p16 $6^{\text {INK4a }}$ or MTS1 (multiple tumour suppressor 1) is a protein encoded by gene CDKN2A in humans and is located in chromosome 9p21.3, its major role is in cell cycle regulation by hindering the progression of the cell cycle through phase G1 to S. 14,15

Many studies have found a significant prognostic implication of p16 on surface epithelial tumours. p16 along with p53 is involved in the regulation of the cell cycle and hence considered by many authors as indicators of tumour aggressiveness and therefore the prognosis. ${ }^{16,17}$ Normal p16 expression is heterogeneous (both nuclear and cytoplasmic) and an overexpression or block positivity is considered to be abnormal. ${ }^{18}$

A significant association with tumour grade and p16 expression, i.e. stronger $\mathrm{p} 16$ expression in malignant tumours compared to borderline and benign tumours has been found. ${ }^{15,17}$

Thus, those epithelial tumours that show an abnormal p16 expression are said to have a poor prognosis. ${ }^{19}$ Our purpose was to study the expression of p16 in various histopathological grades of surface epithelial tumours of the ovary and also study the difference in p16 expression in various subtypes of surface epithelial tumours.

\section{METHODS}

This was a cross-sectional study conducted in the Department of Pathology, Government medical college Thiruvananthapuram, from March 2018 to March 2019 after obtaining human ethics committee clearance.

This was a record-based study and all specimens that were histopathologically diagnosed as surface epithelial ovarian neoplasms were included.

\section{Sample Size}

Was 118 calculated by using the formula

$4 \mathrm{pq} / \mathrm{d}^{2}$

$\{p=45.7 \%, q=100-p(54.3), d=20 \% \text { of } p=9.14\}^{(19)}$

\section{Sampling Method}

The first 118 consecutive specimens received during the period of study were included.

\section{Study Tools}

Formalin-fixed, paraffin-embedded blocks of all diagnosed cases of surface epithelial neoplasms of the ovary.

IHC marker p16

Paraffin-embedded, tissue blocks of the cases were selected, 3-5 micron thick sections were taken and stained with p16 IHC marker and the slides were examined for their expression. The p16 expression was scored based on the nuclear and cytoplasmic positivity as follows:

\section{Immunohistochemical Scores 20 \\ 0 ( $0 \%$ positive cells) negative \\ 1 (1-10\% positive nuclei) - weak \\ 2 (11-50\% positive nuclei) - intermediate \\ 3 (51-100\% positive nuclei) - strong}

\section{Data Analysis}

Categorical and quantitative variables were expressed as frequency (percentage). The chi-square test was used to find an association between categorical parameters. $\mathrm{P}<0.05$ was considered the threshold for statistical significance. Statistical analysis was performed by using a statistical software package SPSS, version 20.0

\section{RESULTS}

\section{Age Distribution}

The age group of patients chosen for our study ranged from 30 - 70 years, of which $67 \%$ of patients were in the pre/perimenopausal age group.

\section{Distribution of the Sample According to Histopathological Subtype}

Among the 118 cases of surface epithelial tumours studied, 60 cases were benign, 28 were malignant and 20 were borderline tumours. The majority of these (46 cases) were serous tumours, closely followed by mucinous ( 40 cases) and endometrioid tumours (40 cases) and only 6 clear cell carcinomas and 3 each of Brenner and seromucinous tumours were obtained.

\section{Association of p16 Score and Histopathological Grades of Surface Epithelial Tumours}

Strong p16 expression was found in $50 \%$ of malignant tumours and $81.6 \%$ of benign tumours had weak expression. This association was found to be statistically significant $(\mathrm{P}=0.000)$ 


\begin{tabular}{|c|c|c|c|c|c|c|c|c|c|}
\hline \multicolumn{10}{|c|}{ Histopathological Grade } \\
\hline \multirow{2}{*}{ p16 Score } & \multicolumn{2}{|c|}{ Benign } & \multicolumn{2}{|c|}{ Borderline } & \multicolumn{2}{|c|}{ Malignant } & \multirow{2}{*}{ Total } & \multirow{2}{*}{ Tau - b } & \multirow{2}{*}{$\begin{array}{c}\text { P- } \\
\text { Value }\end{array}$} \\
\hline & No. & $\%$ & No. & $\%$ & No. & $\%$ & & & \\
\hline Weak/Negative & 49 & 81.66 & 10 & 16.67 & 1 & 1.67 & 60 & \multirow{4}{*}{0.62} & \multirow{4}{*}{0.000} \\
\hline Intermediate & 5 & 15.63 & 9 & 28.13 & 18 & 56.26 & 32 & & \\
\hline Strong/Diffuse & 6 & 23.07 & 1 & 3.84 & 19 & 73.07 & 26 & & \\
\hline Total & 60 & 50.85 & 20 & 16.95 & 38 & 32.20 & 118 & & \\
\hline
\end{tabular}
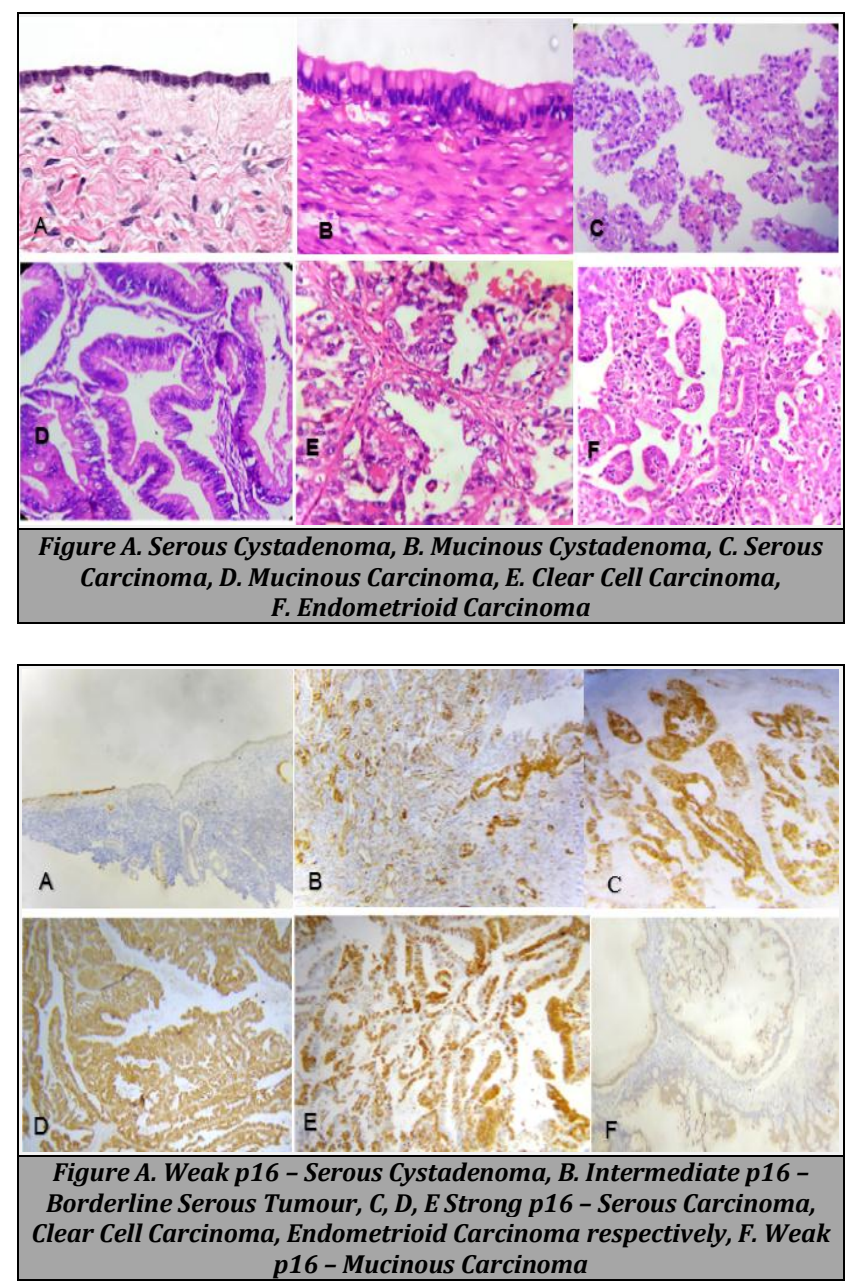

\section{Comparison of Histopathological Subtypes and Their p16 Scores}

A significant association was found between p16 expression and the histopathological subtypes $(\mathrm{P}<0.01) .80 \%$ of endometrioid tumours and $66.7 \%$ of clear cell tumours showed strong p16 expression. $67.5 \%$ of mucinous tumours and $100 \%$ of the Brenner tumours showed weak p16 expression.

\begin{tabular}{|c|c|c|c|c|c|c|c|c|}
\hline \multirow{2}{*}{$\begin{array}{c}\text { Histopathologica } \\
\text { Sub Type }\end{array}$} & \multicolumn{2}{|c|}{$\begin{array}{c}\text { Weak/ } \\
\text { Negative }\end{array}$} & \multicolumn{2}{|c|}{ Intermediate } & \multicolumn{2}{|c|}{$\begin{array}{l}\text { Strong/ } \\
\text { Diffuse }\end{array}$} & \multirow{2}{*}{$\chi^{2}$} & \multirow{2}{*}{$\begin{array}{c}\text { P- } \\
\text { Value }\end{array}$} \\
\hline & Count & $\%$ & Count & $\%$ & Count & $\%$ & & \\
\hline Serous & 28 & 60.9 & 12 & 26.1 & 6 & 13.0 & \multirow{6}{*}{67.6} & \multirow{6}{*}{$\mathrm{p}<0.01$} \\
\hline Mucinous & 27 & 67.5 & 13 & 32.5 & 0 & 0.0 & & \\
\hline Endometrioid & 0 & 0.0 & 4 & 20.0 & 16 & 80.0 & & \\
\hline Clear cell & 1 & 16.7 & 1 & 16.7 & 4 & 66.7 & & \\
\hline Brenner & 3 & 100.0 & 0 & 0.0 & 0 & 0.0 & & \\
\hline Seromucinous & 1 & 33.3 & 2 & 66.7 & 0 & 0.0 & & \\
\hline \multicolumn{9}{|l|}{ \#Chi-square test } \\
\hline Table 2. Compaı & of & 4 & $y$ & 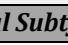 & (n) & & & \\
\hline
\end{tabular}

\section{DISCUSSION}

In our study, we attempted to find out the difference in p16 immunohistochemical expression in various grades and subtypes of surface epithelial tumours of the ovary. Out of a total of 118 cases studied in 1 year period, the majority of patients $(67 \%)$ were in the pre/perimenopausal age group. Among the 118 cases of surface epithelial tumours studied, 60 cases were benign, 28 were malignant and 20 were borderline tumours. The majority of these (46 cases) were serous tumours, closely followed by mucinous ( 40 cases) and endometrioid tumours ( 40 cases) and only 6 clear cell carcinomas and 3 each of Brenner and seromucinous tumours were studied. Strong p16 expression was found in $50 \%$ of malignant tumours and $81.6 \%$ of benign tumours had a weak expression which is similar to a study done by Marinas et al. ${ }^{21}$

In the study by Cabral et al., they found that the difference in p16 expression with different grades of the tumour was statistically significant $(\mathrm{P}=0.000)$ which is comparable to our study $(\mathrm{P}=0.000) .{ }^{20}$ In our study, we found that the difference in expression of p16 among the various histopathological subtypes of surface epithelial tumours was statistically significant $(\mathrm{P}<0.01)$. This was comparable with a study by Cabral et al. ${ }^{20}(\mathrm{P}=0.034)$ and Rambau et al. $(\mathrm{P}=0.0001)^{18}$ in contrast the study by Nazgliou et al. found no such significant relation. ${ }^{17}$

\section{CONCLUSIONS}

The present study found a positive correlation between $\mathrm{p} 16$ expression in tumour cells and histopathological grades of surface epithelial ovarian tumours, with the strongest expression noted in the malignant tumours. Also, a significant relation was observed between p16 expression and the histopathological subtypes of surface epithelial tumours with endometrioid and clear cell carcinomas showing the strongest expression. However, further studies are required to unravel the association of $\mathrm{p} 16$ with patient survival and to establish its prognostic utility in surface epithelial tumours. As the attempts to develop p16 targeted therapy are underway in different parts of the world, such a significant relationship may aid in the early identification of such patients, their further management and hence improvement in their overall survival.

Data sharing statement provided by the authors is available with the full text of this article at jemds.com.

Financial or other competing interests: None.

Disclosure forms provided by the authors are available with the full text of this article at jemds.com.

\section{REFERENCES}

[1] Boyle P, Levin B. World Cancer report 2008. Cancer Control 2008.

[2] Parkin DM, Bray F, Ferlay J, et al. Global Cancer Statistics, 2002. CA Cancer J Clin 2005;55(2):74-108. 
[3] Basu P, De P, Mandal S, et al. Study of 'patterns of care' of ovarian cancer patients in a specialized cancer institute in Kolkata, eastern India. Indian J Cancer 2009;46(1):28-33.

[4] Walker RA. World Health Organization Classification of Tumours. Pathology and genetics of tumours of the breast and female genital organs. Histopathology 2005;46(2):229.

[5] Clement PB, Young HR. Ovarian surface epithelialstromal. In: Mills SE, Carter D, Greenson JK, eds. Sternberg's diagnostic surgical pathology. $5^{\text {th }}$ edn. tumours. Lippincott Williams \& Wilkins 2010:2272-306.

[6] Kanthikar SN, Dravid NV, Deore PN, et al. Clinicohistopathological analysis of neoplastic and nonneoplastic lesions of the ovary: a 3-year prospective study in Dhule, north Maharashtra, India. J Clin Diagn Res 2014;8(8):FC04-7.

[7] McCluggage WG. Morphological subtypes of ovarian carcinoma: a review with emphasis on new developments and pathogenesis. Pathology 2011;43(5):420-32.

[8] Naik P, Deshmukh S, Khandeparkar SGS, et al. Epithelial ovarian tumors: clinicopathological correlation and immunohistochemical study. J Midlife Health 2015;6(4):178-83.

[9] Prat J. Ovarian carcinomas: five distinct diseases with different origins, genetic alterations, and clinicopathological features. Virchows Arch 2012;460(3):237-49.

[10] Modepalli N, Venugopal SB. Clinicopathological study of surface epithelial tumours of the ovary: an institutional study. J Clin Diagnostic Res 2016;10(10):EC01-4.

[11] Swamy GG, Satyanarayana N. Clinicopathological analysis of ovarian tumors--a study on five years samples. Nepal Med Coll J 2010;12(4):221-3.

[12] Kurman RJ, Visvanathan K, Roden R, et al. Early detection and treatment of ovarian cancer: shifting from early stage to minimal volume of disease based on a new model of carcinogenesis. Am J Obstet Gynecol 2008;198(4):351-6.

[13] Makhija P, Singh N. Surface epithelial tumours of the ovary. In: Farghaly SA. Advances in diagnosis and management of ovarian cancer. Springer 2014:59-86.

[14] Stone S, Jiang P, Dayananth P, et al. Complex structure and regulation of the P16 (MTS1) locus. Cancer Res 1995;55(14):2988-94.

[15] Romagosa C, Simonetti S, López-Vicente L, et al. P16Ink4a overexpression in cancer: a tumor suppressor gene associated with senescence and high-grade tumors. Oncogene 2011;30(18):2087-97.

[16] Kudoh K, Ichikawa Y, Yoshida S, et al. Inactivation of p16/CDKN2 and p15/MTS2 is associated with prognosis and response to chemotherapy in ovarian cancer. Int J Cancer 2002;99(4):579-82.

[17] Nazlioglu HO, Ercan I, Bilgin T, et al. Expression of p16 in serous ovarian neoplasms. Eur J Gynaecol Oncol 2010;31(3):312-4.

[18] Rambau PF, Vierkant RA, Intermaggio MP, et al. Association of p16 expression with prognosis varies across ovarian carcinoma histotypes: an Ovarian Tumor Tissue Analysis consortium study. J Pathol Clin Res. 2018;4(4):250-61.

[19] Khouja MH, Baekelandt M, Nesland JM, et al. The clinical importance of Ki-67, p16, p14, and p57 expression in patients with advanced ovarian carcinoma. Int J Gynecol Pathol 2007;26(4):418-25.

[20] Cabral VD, Cerski MR, Sa Brito IT, et al. P14 expression differences in ovarian benign, borderline and malignant epithelial tumors. J Ovarian Res 2016;9(1):69.

[21] Marinaş MC, Mogoş DG, Simionescu CE, et al. The study of p53 and p16 immunoexpression in serous borderline and malignant ovarian tumors. Rom J Morphol Embryol 2012;53(4):1021-5. 